\title{
Keynote Conversation
}

\author{
Ray Boshara and William A. Darity, Jr.
}

Ray Boshara: We're here, as you know, with William "Sandy" Darity of Duke University. And I first of all want to thank Sandy for his flexibility. He was signed up to do a closing reflection, and it was just turned into a keynote conversation. So I've put a little bit more thought into a few more questions to think about. But we're thrilled that you're with us.

And, as many of you know, Sandy Darity is the Samuel DuBois Cook Professor of Public Policy first, African-American Studies second, and Economics at Duke University where he also directs the Samuel DuBois Cook Center on Social Equity at Duke University, former Chair of the Department of African and African-American Studies, and a founding director of the Research Network on Racial and Ethnic Inequality at Duke. Many other things as well. One thing that I did note though is he is also the director of the Undergraduate Honors Program in Economics, and the part that surprised me most, director of Graduate Studies at the University of North Carolina. Now I understand there's a basketball rivalry between Duke and UNC. And how did you get away with that, that affiliation? And where do you sit during the basketball games?

William “Sandy" Darity, Jr.: I'll only say that I have season tickets to the Carolina basketball games. [Laughter.] That's all I'll say on that.

Boshara: And I understand that when you're not thinking about the racial wealth gap, you play the harmonica with a blues group. Is that correct?

Darity: I do occasionally.

Boshara: Did you bring your harmonica?

Darity: I didn't.

Ray Boshara is senior adviser and director of the Center for Household Financial Stability, Federal Reserve Bank of St. Louis. William A. Darity, Jr. is the Samuel DuBois Cook Professor of Public Policy at Duke University. This is a transcript of the keynote conversation presented at the symposium, "Does College Level the Playing Field? Racial and Ethnic Differences in Family Wealth Among College-Educated Families," sponsored by the Center for Household Financial Stability and the Research Division of the Federal Reserve Bank of St. Louis, May 25-26, 2016. It has been lightly edited for readability.

Federal Reserve Bank of St. Louis Review, First Quarter 2017, 99(1), pp. 103-20. http://dx.doi.org/10.20955/r.2017.103-120

(c) 2017, Federal Reserve Bank of St. Louis. The views expressed in this article are those of the author(s) and do not necessarily reflect the views of the Federal Reserve System, the Board of Governors, or the regional Federal Reserve Banks. Articles may be reprinted, reproduced, published, distributed, displayed, and transmitted in their entirety if copyright notice, author name(s), and full citation are included. Abstracts, synopses, and other derivative works may be made only with prior written permission of the Federal Reserve Bank of St. Louis. 
Boshara: Oh. Okay, next time we'll have to do that.

Darity: Next time, all right. [Laughs.]

Boshara: Well, great. We're really fortunate that you're with us today for this conversation. I'm going to start off with a few questions for Sandy. And then we're going to open it up to all of you. So let me begin with this here. I really like the paper that you and Darrick Hamilton and Anne Price and others did called "Umbrellas Don't Make It Rain." What did you mean by that? What are you trying to get at by this concept of umbrellas don't make it rain? And why is that important for our symposium?

Darity: Okay. Before I get to that, first I'd like to say thank you to you-

Boshara: Sure.

Darity: - and to Bill and to Lowell for having this event. It's really unusual for researchers to find - to come up with a finding that is a puzzle to them, an important puzzle, and then to build the conference around that important puzzle. So I've got to applaud you all for that, so thank you.

Boshara: Well, thank you very much. I appreciate it.

The Homeownership and Mortgage Experiences Q and A: [Applause.] And also, as you've mentioned, Darrick and Anne Price have been collaborators on this paper, "Umbrellas Don't Make It Rain." And both of them are here. Folks have heard from Darrick, and I guess Anne asked a question at the end of the last session.

\section{Boshara: Yes.}

Darity: I'd also like to mention Kilolo Kijakazi in the front row, who, while she was at the Ford Foundation made it possible for us to pursue a phenomenal research project where we could look at the wealth position of communities of color in five cities in the United States. And we hope that maybe St. Louis could...

Boshara: We were just talking to somebody at the Board about that very possibility.

Darity: Oh, this is good. Okay. So let me talk a bit about "Umbrellas Don't Make It Rain." The point of the title is to make the distinction between the classic difference between association and causation or correlation and cause and effect. So, you know, we would obviously make the observation that, when it rains, there's a high presence of umbrellas on the streets or on the sidewalks.

Boshara: Like this morning.

Darity: Yes. 
Boshara: Yeah, okay.

Darity: But we should not infer that umbrellas have caused the rainfall to take place. Okay. And so, similarly, if we observe that people with higher levels of education have higher levels of wealth or people with better health outcomes have higher levels of wealth, we should not necessarily infer that educational attainment is driving the wealth outcome or the health outcomes are driving the wealth outcomes. We can't conclude that education causes wealth to be higher or that better health causes wealth to be higher.

In fact, the reverse causation with respect to education was one of the big points that $\mathrm{Su}$ Jin Jez made yesterday. And I'm also appreciative of the fact that Bill Emmons and Lowell Ricketts took a great deal of care in avoiding making those kinds of causal claims yesterday. And I'm very enthusiastic about their efforts to frame the analysis of education and wealth in the context of this post-racial versus a structural racism perspective.

But there's still a problem, and I think it's a problem which Su Jin and Molly Metzger and Darrick have all mentioned. The estimation techniques that we use typically are motivated by some assumptions we make about cause and effect. So the appropriate estimation technique is contingent on what we believe is the causal structure of the model. So, you know, I was brought up that you're not testing causation when you do these kinds of estimates. You're actually just trying to look at what the magnitude is of the effects that are in question.

And so, you know, whether you use ordinary squares or something more complicated is really contingent on what you believe the causal structure is. And so when we have estimates of the type that were shown to us at the beginning of the day yesterday, those estimates really are predicated on some sort of implicit assumption that everything that's on the right-hand side of the equation is determining what's on the left-hand side of the equation.

And so we run into a problem if we have on the right-hand side of our equation different types of assets and debts, which are necessarily components of net worth, because essentially what we're doing is we're estimating an identity or a definition. The best that we can say from that is that we've performed some type of an accounting exercise. But we can't really derive a narrative about what are the factors that cause differences in wealth. So we would at least need some sort of model that was based upon simultaneous causation at minimum.

And, you know, we could even argue that age is endogenous to the extent that wealth might affect the longevity of people's lives. Okay. So we have to go back to square one to develop a sound causal model. And my inclination at this point is to think that prior parental wealth during childhood might provide us the best anchor for determining a child's adult wealth. And so, you know, increasingly, I have been trying to think about how we might analyze that quite systematically. And that's sort of the foundation for the work I would like to see us push further on.

And I want to add that looking at inheritances does not adequately capture that relationship. There's also what we call in vivo transfers, which is just the fancy name for transfers 


\section{Boshara and Darity}

that occur across generations while the donors are still alive. Okay. It's a kind of donation I'd like to make to my kids. So we don't measure that satisfactorily, because frequently what constitutes a transfer that takes place while the donors are living is not perceived as such. So, for example, parents might support their kid going to college or university, and if you ask the son or daughter have they received a gift from their parents, they might not actually report that as a gift, because that's what parents are supposed to do. Right? And so we don't adequately measure those kinds of transfers. In addition, the timing of those transfers is critical.

And then the final big point I want to make about prior parental wealth is, in some sense, it sets a stage for opportunity for the child. So even if we don't observe direct transfers in the form of inheritances or in vivos, we still can have a situation where prior parental wealth is creating a more secure economic environment for young people that gives them a chance or a springboard for better success later in life. So...

Boshara: And hence your advocacy of the baby bonds and the child trust funds, which we'll come back to a little bit later.

Darity: We'll come back. Yeah.

Boshara: That makes a lot of sense. So let's stay on the Bill Emmons paper for just another minute. And, you know, we all appreciate the comments. We hope that that framing is helpful. Of course with a structural framing, there's a lot we don't understand. But my guess is that you might be more inclined to think that the structural causes are probably more driving some of these inequalities than, say, the behavioral model.

So if that's correct, Sandy, then, you know, what is the role for choice and human agency and executive function into these terms? I mean, financial capability, you know, Angelyque's comments yesterday I think were suggesting that there's still a really important agenda for that work. So if these families are facing these structural barriers and, in our own research, we're discerning greater headwinds among minority, young, and less-educated families, you know, how do we think about the proper role and even strengthen the ability of financial capability to move families forward?

Darity: So I think that a key distinction for our conversation over these two days is between those factors that affect differences across individuals in the generation of wealth and those factors that dictate differences across social groups and wealth. And so I would submit that behavioral differences may be a partial explanation for the former-that is, individual variations.

So if we were to look within a group-like if we looked within the Black community or we looked within the Latino community-we might find that there are behavioral differences which are influencing who has a better wealth position and who doesn't. I'm not going to say that it's determining, but it is affecting it, okay. But if we look at differences across the groups, behavioral factors don't come into play. 
And I would argue they don't come into play at all, because, in principle, what you would have to be arguing is that the group with the worst outcome on average is inclined towards greater dysfunction behaviors-bad choices, ignorance, bad judgments, weaker motivation. I mean, the ultimate implication of this kind of argument is that there's something inferior about the group that has worse outcomes. Now I would argue that there are not proportionately more Black fools than there are White fools. Okay? Both groups have fools.

Boshara: Probably the opposite.

Darity: Some days I'm a fool. But I don't think that the distribution of fools is any different across the two groups.

Boshara: It's pretty widespread.

Darity: [Laughs.] So, insofar as that's the case, then we can't really make a satisfactory argument that differences in behavior across the groups explain differences in wealth outcomes. And in fact, you know, there's some evidence that we've talked about over the course of the past day and a half that I think is consistent with what I've just said. So, for example, if you control for household income, we find no significant difference in Black and White savings rates, and in some income categories the Black savings rate is slightly higher.

We don't find any evidence of any significant difference in rates of return on portfolios after you control for household income. So, if you control for household income, Blacks actually get more years of schooling than Whites and more credentials. And one of my takeaways from Cory's talk earlier today was that, in some sense, Blacks actually overachieve educationally, relative to Whites. And so, again, you know, this would not suggest at all that there's some greater dysfunction that's occurring in the Black community relative to the White community.

And one last point in this context. We frequently talk about money management problems or people who make bad financial decisions. And I would suggest that maybe actually lower-income people are better money managers than higher-income people, simply because they have to be. And individuals who actually have relatively high levels of financial literacy can mismanage. For example, I'm thinking about the victims of Bernie Madoff's Ponzi scheme. I would hardly think that anyone would say that those are folks who were financially illiterate. Okay.

And in fact you might even argue that they would be more susceptible to fraud because of their confidence in their own capacity to manage their portfolios. So, you know, I think we really have to think carefully about the resource conditions that individuals and families are faced with. And those resource conditions, the distribution of those resource conditions, is really in my view decisive in shaping the distribution of wealth.

Boshara: Interesting. Yeah, very good. So, sticking with the race thing here for a minute, you're no doubt familiar with Robert Putnam's important book from last year, Our Kids, 


\section{Boshara and Darity}

where he argues that the most troubling finding in America is actually not a racial divide. It's a class divide. And the class divide is being driven, really, by two things. Are your parents-speaking of kids and their future, are your parents college educated, and are they married? We heard in the last session the importance of marriage and having a degree for wealth accumulation.

So, you know, and he says that basically about a third of kids have married, well-educated parents, and they're going to be fine. But up to two-thirds of kids potentially are facing a very bleak opportunity structure, one very different than even a generation or two before. A lot of reasons for that-breakdown in the community, changes in family structure, economic forces, of course. So, you know, do you-I mean, do you agree with Putnam's analysis that it's primarily a class divide that we should be worried about? And if you do think that he's right, then what is the significance of race then in thinking about mobility for kids?

Darity: Well, obviously, I'm going to say I don't think he's right. I think everybody in the room would have predicted I might say that. But I think it's because there are some complications here that-it's not because his observation is wrong. It's because of his interpretation of what that observation means. So, you know, is the problem that a child grows up in a single-parent family? Or is the problem that that single-parent family doesn't have a significant amount of resources?

And, you know, this is anecdotal. And I shouldn't live on anecdotes, but I will use this one. You know, for the year, I'm living on the Upper East Side, courtesy of the Russell Sage Foundation. Okay. So I would warrant that the children who live in single-parent families in the East Sixties and East Seventies in New York City are not going to have bad wealth outcomes. Okay. But they might be in single-parent families.

In addition, we know that there are other parts of the world, particularly the Scandinavian countries, where there's a high incidence of single-parent families, but there's not the associated deprivations. And so, again, it's really contingent on whether or not the families have adequate resources. It's not exclusively a question of family structure.

Boshara: But isn't the divide really among single-parent families with a college education versus those without? I mean, the real rise in single-parent families since 1950 has been among non-college-educated parents.

Darity: But if we go back to the racial wealth gap, we find that Black and White families with similar structures, similar educational patterns, still have vast differences in their net worth position. And so there's something that race is doing in this society that is producing these kinds of significant differences. I would argue that, in some sense, race drastically alters the odds of both your social class location, but also the wealth position that you may have access to in this society. 
And we know from Dalton Conley's work that Black kids who are born into two-parent families where both of the parents are college educated have a much greater likelihood of downward mobility in the next generation than White kids who were born in similar types of families. And so there's something else going on besides social class.

And I'd like to add that, you know, one of the things that became apparent in our conversation yesterday is that there probably is a need for more research about what the labor market outcomes and wealth outcomes are for individuals who have gone to the same schools, completed similar degrees, and proceeded into the labor market. And we do have some preliminary evidence on that.

So there's a study by Janelle Jones and John Schmitt, which finds that Blacks with engineering degrees have much higher unemployment rates than Whites with engineering degrees. But that's still not satisfactory, because we're not sure if the folks have degrees from the same schools. But if we look at Black MBAs from the Harvard Business School, they start their post-degree careers-Black MBAs from Harvard Business School, specifically, start their post-degree careers earning $\$ 5,000$ less than their White peers who've earned degrees from the same program.

In six to eight years after graduation though, the racial pay differential balloons to $\$ 100,000$ per annum. And in a Bloomberg study, they found that the sector with the most inequitable compensation by race and gender is the finance sector. And that's where schools like Harvard, Columbia, and Wharton send most of their grads. So here we have folks who actually have identical degrees but very different subsequent compensation outcomes.

And then there is a study by S. Michael Gaddis, and this one I think is really clever and interesting, but disturbing. So Gaddis performs an audit of more than 1,000 positions advertised on national websites using racialized names. And the way in which he arrives at the racialized names is to use the New York State Department of Health's birth records. He looks at the name and race of the child and the name and the mother's education.

And so then he creates these false profiles. And he uses the following names-Jalen, Lamar, and DaQuan for the Black males, Nia, Ebony, and Shanice for the Black females, Caleb, Charlie, and Ronny for the White males, and Aubrey, Erica, and Lesley for the White females. And then he assigns them to schools, one set of schools that's highly selective and another that's less selective, although it may be somewhat selective. So he pairs Harvard with the University of Massachusetts at Amherst. He pairs Stanford with the University of California at Riverside. And he pairs Duke with UNC at Chapel Hill. Okay? (Laughter.)

There you go. Okay. So despite the fact that-and then he submits these full resumés and tries to see if he gets callbacks for the individuals who are hypothetically applying for these positions. So, despite the fact that the credentials from highly elite schools improved the employers' response rate, candidates with White-sounding names from the less-selective schools received as strong a response as Black candidates-as the candidates with Blacksounding names from the more-selective schools. Okay? 


\section{Boshara and Darity}

And when the employers responded, they offered the Black candidates lower starting salaries and lower status positions than Whites with similar or even inferior credentials. And I was saying they treat-in this exercise he treats all of the applicants as either economics or psychology majors, so not allegedly soft majors per se. So, I mean, I think it's pretty compelling that, you know, there's something more going on than social class differences, that the way in which social class gets assigned is a function of the way in which race is treated in American society.

Boshara: Very interesting. So, speaking of institutions, Su Jin yesterday made I think an interesting comment right there at the end that it might be better to try to change the institutions instead of trying to change the students, that institutions need to adapt, not really the other way around. If you think that's correct, let's use the example of Duke University. What would change at a university like Duke, you know, if they were to try to be a little bit more sensitive to who kids are today? Who are college kids today?

Darity: Well, okay, so let me say something a little bit ugly. Okay. So Cory's coauthor is Peter Arcidiacono. And work that Peter does-not with Cory, as far as I know-focuses on what's called the mismatch hypothesis. The argument that's being made is that Black students frequently would be better off going to less-selective schools, because when they go to highly selective schools, they're not sufficiently prepared to be successful there. Okay. And, usually, the criteria that's used for determining whether or not they are well prepared is some gauge of some type of test score.

That's a bit different from what you all were doing with the Missouri data by looking at actual - the ostensible quality of the public school that the student attended and so forth. But the college-level studies are usually focused on test scores. And so there's a test score gap and then presumably that's an indication of a preparation gap. So there is also this phenomenon that Darrick introduced into the conversation a little bit earlier of something that we call stereotype threat.

This is work that was produced by social psychologists like Claude Steele. So he's the good Steele, okay. He has a twin brother, Shelby, who-they live in different worlds even though they're identical twins. Okay. So, yeah, that's great for twin studies. So Claude has argued that the existence of biases and stereotypical beliefs about a social group's capabilities in a particular arena will actually affect the performance of members of that group in that arena. And this is even if the individuals don't believe the stereotype about their group.

They will be doing their best to not prove the stereotype or to not reinforce the stereotype, and that puts too much pressure on them in trying to perform the task at hand. And so it depresses their outcomes. And so this is an issue, because it means that the scores that we observe for a group that is subjected to stereotype threat might be depressed. And then there's the issue of how much they're depressed. And we can talk about whether there should be more research done on this. 
But I want to go back to the stereotype threat itself, which is, you know, the existence of these beliefs. So suppose you have a faculty member at your school whose ostensibly scientific research is saying that you should not be there. That constitutes stereotype threat in its most ferocious form to me.

And so I would argue that, unfortunately, the very type of work that Peter is doing is reinforcing a climate that has stereotype threat embedded in it. And so that's something that universities can change, is this attitude or outlook or belief that is perpetuated that certain groups of students really shouldn't be there at all. Okay. So that's the internal change.

Boshara: So there's a lot of work to do beyond admissions?

Darity: Yes. Yeah. Yeah. Yeah. And, you know, the other thing that emerges in Peter's work is this observation that Black students shift from the STEM fields more frequently than White students do. And I would argue that that's not simply because they find those fields to be too difficult. It's also because of how they're treated by the faculty members and their peers when they try to go into those fields. So that's another thing that needs to be addressed.

So I think that there are some internal climate issues that really do have to be addressed. But I also think that there are some structural conditions external to the university that are critical - that we want to have a situation where more and more students don't have to worry about the financial dimension of their education. And I think that there is a larger proportion of Black students who do have to worry about that. I think it was, you know-

Boshara: Right. They also can't get into Harvard with its substantial endowment to take care of their tuition.

Darity: Right, or Princeton where people wonder why they even charge tuition. But, you know, that's another issue.

Boshara: Right. Right. So I have just a couple more questions about sort of responses and solutions before we open it up. So, thinking beyond the university, there's a Brookings paper out by Isabel Sawhill and Richard Reeves that cites you and Darrick as proponents of what are called race-conscious policies. So, what exactly is a race-conscious policy, and how is that different than, say, a race-based policy? And so you think there is some promise with that approach?

Darity: So I guess, instead of race-based, I'd like to say race-specific.

Boshara: Race-specific. Sure. Okay.

Darity: So a race-specific policy is a policy that targets a particular group, a particular racial group. I mean, I'm using the term race. It could be caste-specific. It could be gender-specific. But there's a particular group that's being targeted by the policy. 
A race-conscious policy, in contrast, is one in which the policy is applied universally, but it's applied universally in such a way that the group that's in the relatively deprived position gets a disproportionate benefit. So it's not race-neutral, but it's also not race-specific. And so that's what we mean by that. And I think that they had in mind in that particular article our baby bonds proposal.

Boshara: Yes, that's the specific example, which was my next question. But it's a great segue.

Darity: Okay. So the baby bonds idea is not-it's not a bond. It's really the provision of an endowment to every newborn infant in the United States. And so the idea is that wealthy families typically create endowments or trust funds for their children. So why shouldn't every child have a trust fund or an endowment? What's a little bit unique about this particular proposal though is we don't think that every child should receive the same amount in an endowment, that the endowment amount should be stratified based upon the family's wealth position.

And so, you know, in my stump speech I usually say if Oprah Winfrey or Bill Gates had a new child, we'd give them a $\$ 50$ endowment. But for children who are born into families at the lowest end of the wealth distribution, we'd give them a $\$ 50,000$ or $\$ 60,000$ endowment. We would guarantee a 1 percent real rate of interest on these accounts, and they could access them when they turn 18 years of age.

If we are concerned that these kids will make foolish decisions, since it's public funds, then I guess we're not completely disturbed about the idea of placing restrictions or limits on what the funds can be used for, although that is paternalistic. But, you know, that's okay. It's public money. So that's the basic idea. Why is it race-conscious? Well, it's raceconscious because the wealth distribution looks so different for Blacks from Whites, and so there would be disproportionately larger endowments going to Black kids than White kids on average.

Boshara: So something [overtalk 00:33:05].

Darity: But everybody gets something.

Boshara: So this is a more radical version of the proposals that are actually in law right now in the U.S. and throughout the world and have been proposed in legislation where the bump-up for poor kids-usually by income, not by race-has been twice, you know, maybe, so $\$ 500$ for all kids was a bill I worked on when I worked in the U.S. Congress and $\$ 1,000$ for poor kids. And you're proposing something far more-

Darity: Far more.

Boshara: - ambitious and based on wealth with an explicit focus on race.

Darity: No. No, no. I'm saying it's a universal program. 
Boshara: No, no, no, but I'm saying—no, but the supplemental deposit would be based on-

Darity: No. No, no. No, there's no supplemental deposit. There's a fixed deposit that everybody gets.

Boshara: Everybody gets.

Darity: That everybody gets.

Boshara: Right.

Darity: But it's based upon the wealth position of the family.

Boshara: No, I understand.

Darity: So the only argument I'm making is that there are proportionately more Blacks at the lower end of the wealth distribution.

Boshara: Right, right.

Darity: So those kids would get the larger deposit. Okay? So it's race-conscious in that sense. But, no, there's no premise involved in the allocation of the funds that's predicated on the race of the recipients. So this is different from another program that I think we need to give serious consideration to, but people always scoff, which is reparations, which would be a race-specific program.

Boshara: Right.

Darity: But the baby bonds proposal would be for all American kids. Yeah.

Boshara: Yeah, fascinating. Well, for those of you who don't know, this is happening here in St. Louis. In two different communities all kids entering kindergarten get an account through the efforts of the city treasurer, Tishaura Jones, and then all kids entering kindergarten in the Normandy School District where Michael Brown graduated get $\$ 500$ at birth. But this is a different and more ambitious proposal. Has there been any response to that proposal?

Darity: Well, I mean, I thought that it was pretty striking that Isabel and Richard would actually write a blog saying, "Yeah, this is a pretty good idea." So I think that that is an indication of some momentum in that direction. There's also a couple of Congress people who have said that this was something that was of interest to them.

I want to distinguish this proposal though from the savings accounts proposals, because there is no-in the proposal that Darrick and I have developed-there is no obligation for families to make any kind of matching commitment to the fund. And in fact we don't 
want them to do that. You know, if parents are-if wealthy parents want to set up a separate trust fund for their kids, fine. But we don't want to contaminate the public fund with differential contributions that are coming in from families that are at vastly different wealth positions. So there's no savings component to our program at all.

Boshara: Interesting. Well, the proposals that do have that, they cap that to prevent, you know, tax shelters and things like that.

Darity: Yeah.

Boshara: Great. Well, fascinating. I think there's a lot of promise with that. It's great to hear about. And thanks to Kilolo and the Ford Foundation, these proposals are existing all over the country and are moving forward, back at her days at Ford. And we'll have a chance to hear a little bit more from Kilolo in just a minute.

Boshara: Okay, I'd like to use our last 15-20 minutes to open it up. Just remember to state your name and affiliation, okay, before you ask your question. Here and then here. Yes, thank you. Uh-huh?

Mary Anne: Mary Anne from SIUE. And I know that Linda Babcock did some research dealing with women's first salaries and the fact that they didn't negotiate their first salary. Has there been any work done looking at different ethnic groups in terms of-you mentioned the Harvard MBAs that would start at \$5,000-has there been any research looking at negotiating your first salary?

Darity: So it's my understanding - and I'm not sure that I've got a good answer to that question-but it's my understanding that the difference is a gender difference, not a race difference. So Black men, White men will negotiate hard for the first salary. And women, whether Black or White, will not typically negotiate as hard for the first salary. So it's a gender gap. It's not a race gap.

Mary Anne: So there's nothing that's-they haven't looked at that and said-

Darity: I've never seen any evidence to suggest that there was a racial difference in negotiating practices. Now there might be a difference in terms of information about what the possibilities are, but not in terms of the intensity with which men, whether Black or White, attempt to negotiate that first salary. Yeah.

Boshara: Thank you.

Whitney Barkley: Hi, I'm Whitney Barkley with Center for Responsible Lending. So I just had a question about the kind of functional-I love the idea of the baby bond, and I just was wondering about a couple of functionalities. So, if the child gets access to the bond at 18 and we're talking about sort of the need for a financially secure childhood, then there 
is a generation that wouldn't have the benefit of that baby bond, at least for that first generation.

So we're not going to really see a change in their circumstances until they turn 18 . So what is sort of the back-end ideas, you know, for helping that first generation? And is this the idea that eventually we would stop issuing these baby bonds because there would be more financial stability? Or would this be something that would continue sort of indefinitely?

Darity: So, to answer the second part of your question first-I have always thought of this as something that would be indefinite, because it would be a mechanism for trying to correct for the degree of inequality that exists at any point in time. So, you know, the program could be eliminated if you wish if everybody was at the median net worth. But even then, we might still want to give every child some endowment that's consistent with being at the median net worth so we could have a uniform endowment. No, but I think of this as something that would be a permanent program.

With respect to the first question, we wanted to ensure that we didn't have the issue of badly behaved parents having control over these funds. And so that's why we set the adulthood standard for receipt of the funds. But if we are deeply concerned about forms of deprivation and poverty, there's another proposal that we have which we think could address that. And this is what we call the Federal Job Guarantee.

There's a companion set of ideas that are gaining more and more attention lately that are called the Basic Income Guarantee. Not averse to that. I have a preference for the job guarantee, although you could have both if you wanted. They're not necessarily mutually exclusive. But the premise here is that every American would be assured of employment at non-poverty wages in the public sector.

So this would be the universalization, if you will, of the Works Progress Administration and the Civilian Conversation Corps from the Great Depression era. It would be the universalization of it and would also be something that was made permanent. And so, you know, if we're concerned about people's motivation and who is not willing to work, we certainly could find out if we had a Federal Job Guarantee. Yeah.

Boshara: And I would just add that I think a lot of these proposals, you know, they're not standalone. They're a complement to some other interventions that are targeted to families, so helping them build emergency savings and liquidity, you know, helping getting their balance sheet in order. You have to address the financial needs of the families if you want the kids to succeed. This is meant to be distinct and separate and a little bit longer term.

Darity: And I would say that, you know, if we were giving kids these trust funds, then we would have a strong reason for them to have financial education. And, you know, maybe we'd build that directly into the curriculum in our schools. 


\section{Boshara and Darity}

Boshara: Well, the best ones have done exactly that. They sort of rewrite the curriculum based on these deposits, and it's proven to be-

Darity: Very helpful.

Boshara: — very effective and very—yes very helpful.

Brent Neiser: Thanks, Ray. Brent Neiser, National Endowment for Financial Education. I just-a couple of comments. Baby bonds to me tangibilize the intangible. And the idea of really grounding the idea of assets and what those are can be an example that you could use this as a reference point. And families will-this will be now dinner discussion, intergenerational, making this-showing what a baby bond is compared to housing equity.

The work John Rogers of Ariel Capital Management and Mellody Hobson has been constantly trying to move the ownership of equities in minority communities. So I think it's got great, great potential. And there are also lessons to be learned from the income distribution situations on Native American reservations and per capita distributions of money from resource-rich and gaming tribes as well as what's happening right now in Alaska with the decline of revenue sharing from oil revenues from the Alaska Pipeline.

That check that's been going to Alaskans of, I assume all over 18, it's starting to decrease. So we have examples of where income distributions and sharing and revenue sharing fall short and are not teachable moments. The baby bonds have much more opportunity to really change, major change power. So keep thinking about it.

Boshara: So I'm going to take two more questions, Sandy, and then give you a chance. So Bob and then Steve, and then we'll respond at the end here. Uh-huh.

Robert Lerman: More to give some perspective on the past programs. You know, I worked in the Carter administration, and we did propose a job guarantee. But we got actually as much opposition from the left as we got from the right on that. I can go into the details. But in any such program you would want to have wage subsidies such that jobs in the private sector wouldn't be discouraged.

On bonds, I think it's a very interesting proposal. And I think that one of the things that we ought to be looking at is the entire spectrum of spending on young people. If you think education doesn't matter that much, maybe we might reduce especially some of the-at the higher education level, some of the-

Darity: I've never said education doesn't matter. (Laughter.) I don't know why this keeps coming up. What I've said, and I think that some others have said, is that educational attainment doesn't make much headway in closing the racial wealth gap.

Lerman: Yeah. Okay. 
Darity: Okay. [Laughs.]

Boshara: But that doesn't mean you don't do it. No, absolutely not.

Darity: No, no. And in fact, you know, I'm a passionate advocate of eliminating tracking in schools and moving towards having gifted education for all students. Okay. So I believe strongly in the importance of education. I'm just-you know, I'm just absolutely convinced that, you know, more education is not going to do much to close the racial wealth gap. That's all.

Boshara: Right. Okay. So did you—are you good?

Lerman: I'll let someone else talk.

Boshara: Thank you.

Lerman: But the job guarantee-oh, just one more point on the economy, is I don't know whether you're aware of this, but Charles Murray has proposed an income guarantee of $\$ 25,000$. But it would replace other income guarantees. But $\$ 25,000$ per adult every year. So maybe you can make common cause with me.

Darity: Maybe. That would be a miracle, but maybe. [Laughs.]

Boshara: Oh, we brought Santorum, Corzine, Schumer, and DeMint together around our baby bond proposal 10 years ago. Okay, we'll take one final comment from Steve, and then I want to let Sandy make a few closing comments.

Stephen Ross: Well, Sandy, I just wanted to ask about-you must know the Sendhil Mullainathan and Eldar Shafir book on poverty, right?

Boshara: Scarcity: Why Having Too Little Means So Much.

Ross: This is the one where they talk about scarcity and this idea that people who are faced with a $\$ 400$ bill, they just - they can't make this-because they can't afford it, they can't make decisions well. They make bad decisions. They can't plan. And the more scarcity you face, the worse this problem becomes.

Darity: Right.

Ross: And I'm wondering about that in terms of wealth. And I want your reaction here, right? Because if you think about it, there's so many Americans that have so little wealth that that then becomes this possible very large effect of wealth on outcomes in the future for these families, because if people don't have more than $\$ 1,000$ in the bank or more than $\$ 200$ in the bank, they've got no cushion. And have you thought about the Sendhil Mullainathan book and how that might relate to the impact of wealth on family outcomes? 


\section{Boshara and Darity}

Darity: So I think that's precisely why I think there is a complementary dimension to either a basic income guarantee or a job guarantee with the child trust fund approach, that we do have to in some way address the adult generation's impoverishment. So I like to make a distinction between income poverty and wealth poverty. And so I think of the job guarantee as an avenue for addressing income poverty.

And I think of the baby bonds proposal as an avenue for addressing wealth poverty. And they're not the same things. But there is a need for some sort of complementary set of programs to try to address the issue that you're concerned about. I will say this though. I think Jonathan Morduch's work actually-

Boshara: The Financial Diaries.

Darity: The Financial Diaries actually suggests something a little bit different, which is that, yes, these families have very little, but they actually do remarkably well with what they have, which is a bit different from the Mullainathan position. Yeah.

Boshara: Yeah. It's an important book. I mean, their basic insight is that people are not poor because they make bad choices. They make bad choices because they're poor. And that cuts across. It's an important book. And speaking of asset poverty, many of you are familiar with CFED's work on the asset scorecard and coming up with a definition of assets poverty. And of course, just like wealth inequality, asset poverty is much greater. Looks like Angelyque wants to get a final comment in here before I wrap up.

Angelyque Campbell: I think Sandy will be able to wrap this up in his comments. So the other interesting trend that's going on is the graying of America along with the diversity of America. And I'm just curious-

Darity: I know something about that. [Laughter.]

Angelyque Campbell: Didn't mean to make any references. But, you know, I'm trying to understand how we can start changing this narrative about the racial wealth gap to where folks understand that we're all in this together. And right now, those who are still influencing the direction of public investments are those who do not see the children coming up in the future looking like them. So how do we start building this new narrative to kind of promote this social equity framework and get out of this narrative of us versus them?

Darity: Well, I mean, I think that that's one of our motives for thinking in terms of a universal program, even if it's graduated, a program that everybody has-potentially has a stake in, that that's a way of defusing that kind of notion that it's just for them, it's not for us. So I'm not sure if that's entirely enough to do it. But both the baby bonds proposal and the job guarantee are conceived as universal programs. They're for everyone.

Everyone could-every child would receive the trust fund and everyone who wanted to take the public sector job could do so. So I think it's this notion of the universal dimen- 
sion to these proposals. Now people may still flinch because it's race-conscious in some sense. But race specificity I think is harder to sell than a race-conscious program that everybody actually can participate in.

Boshara: So one final question, Sandy. We know we have two more sessions yet to go on home ownership and on family transfers, which you mentioned earlier. But what have you heard so far at this symposium that's new or interesting or, you know, has changed that way that you are thinking about these issues?

Darity: So there was a question yesterday-I'm not sure if the person who asked it is still here-about well-being and happiness. No. Well, anyway, I thought that was a very interesting question. And I had some thoughts about it, but I think it's an area that we might want to explore further. We know a bit about happiness. And the ironic thing is that people are happier if they are doing better than whoever their reference group is. This is somewhat unfortunate, but that's-so it's not absolute status that matters so much as it is relative status.

And then there is the question of who is the comparison group. And so I think that this is an arena that we might want to explore. It has implications for the question that you just asked, Angelyque, is how people conceive of well-being and relative position and who it is they're comparing themselves against. So that's one project. A second is maybe figuring out ways in which we can simulate in a comparative way various kinds of interventions to affect the wealth distribution.

So whether it's the programs that are already in existence that provide all kids with a flat rate, versus the baby bonds proposal, can we set up a model that we all have some degree of confidence in that could give us a projection about how the wealth distribution would ultimately be affected by introducing these kinds of policies? So I think that that would be something that would be very, very useful.

Also, I think that Cory's study, which places the location for poor school outcomes at the college and university level on what happens to kids when they are in K through 12, really points us back to this whole issue of, "How do we improve curriculum and instruction for kids who are denied that kind of quality of education now?" I think we know how to do it, but I don't think that we do it. And I think that that's another area that requires substantial attention.

And I guess the final thing is, I really like the construction of a juxtaposition between the post-racial and the structural racism narratives. But I also think we should think aboutand I think that's useful going forward in terms of doing new research-but I also think we might want to think about a labor economics versus a stratification economics view of the world.

So, in the labor economics view of the world, in my understanding - this is going to be fairly crude-is that the same factors that dictate earnings and income outcomes also 


\section{Boshara and Darity}

dictate wealth outcomes. And the stratification economics view says no, that the central factors that dictate wealth outcomes have to do with transfers across generations. And that's a different story. And so I think we need to do more work to explore those kinds of differences and perspectives and what the implications are for policy.

Boshara: Maybe that will come up in Tom and Tatiana's session in a little bit. Okay. Well, this was fascinating. Thanks for your flexibility. And thank you very much. [Applause.] 